\title{
Galectin-1, an alternative signal for $T$ cell death, is increased in activated macrophages
}

G.A. Rabinovich, C.M. Riera and C.E. Sotomayor

\author{
Laboratorio de Inmunología, Departamento de Bioquímica Clínica, \\ Facultad de Ciencias Q uímicas, Universidad Nacional de Córdoba, \\ Córdoba, Argentina
}

\section{Correspondence \\ C.E. Sotomayor \\ Laboratorio de Inmunología \\ Departamento de Bioquímica Clínica \\ Facultad de Ciencias Q uímicas \\ Universidad Nacional de Córdoba \\ Ciudad Universitaria \\ Pabellón Argentina \\ 5000 Córdoba \\ Argentina \\ Fax: +54-351-433-4174 \\ E-mail: \\ csotomay@bioclin.fcq.unc.edu.ar}

Presented at the 5th Brazilian

Symposium on Extracellular

Matrix - SIMEC, Angra dos Reis,

RJ, Brasil, September 7-10, 1998.

Research supported by the Consejo

Nacional de Investigaciones

Científicas y Técnicas (CO NICET),

Consejo de Investigaciones

Científicas y Tecnológicas de la

Provincia de Córdoba (CO NICOR),

and Secretaría de Ciencia y Técnica

de la UNC (SeCyT-UNC).

Received November 17, 1998

Accepted February 10, 1999

\begin{abstract}
Galectin-1 belongs to an evolutionarily conserved family of animal Bgalactoside-binding proteins, which exert their functions by crosslinking the oligosaccharides of specific glycoconjugate ligands. During the past decade, attempts to identify the functional role of galectin-1 suggested participation in the regulation of the immune response. Only in the last few years has the molecular mechanism involved in these properties been clearly elucidated, revealing a critical role for galectin-1 as an alternative signal in the generation of T cell death. In the present study we will discuss the latest advances in galectin research in the context of the regulation of the immune response, not only at the central level but also at the periphery. Moreover, we will review the purification, biochemical properties and functional significance of a novel galectin-1-like protein from activated rat macrophages, whose expression is differentially regulated according to the activation state of the cells. The novel role of a carbohydrate-binding protein in the regulation of apoptosis is providing a breakthrough in galectin research and extending the interface between immunology, glycobiology and clinical medicine.
\end{abstract}

Key words

- Galectin-1

- Apoptosis

- Immunomodulation

- Macrophage

\section{Introduction}

Galectins are a family of evolutionarily preserved proteins widely distributed in species ranging from fungus to man (1). The systematic name "galectins" has been recently proposed, referring to proteins which are characterized by a conserved carbohydrate recognition domain (CRD), binding specificity for $\beta$-galactoside-related sugars and conserved sequence motifs (2). Figure 1 illustrates a structural diagram for the classification of mammalian and non-mammalian galectins. Despite the fact that galectins exhibit classical features of cytosolic proteins, they are definitely exported into the extracellular milieu by a non-classical secretory pathway (3), where they interact with specific extracellular matrix ligands such as laminin and fibronectin $(3,4)$. They may be targeted alternatively to the nucleus or sub-cytosolic compartments (5). Extracellularly, they have been implicated in the modulation of cellcell and cell-matrix interactions through glycoconjugate-mediated recognition.

Based on their molecular architecture, 
Figure 1 - Galectin family. Three architectural types and distribution in mammalian and nonmammalian tissues. galectins have been classified into three groups, namely proto-, chimera- and tandem repeat-types. This classification proposed by Hirabayashi and Kasai (6) was defined mainly according to the architectural features of this protein family, without any functional or evolutionary connotation. Proto-type galectins function as homobifunctional cross-linkers able to dimerize in a non-covalent fashion. On the other hand, chimera- and tandem repeat-types act as heterobifunctional crosslinkers of glycoconjugates. Chimera-type galectins are designed to link carbohydrate and non-carbohydrate biomolecules (e.g., polynucleotides and polypeptides). The tandem repeat-type can cross-link different types of glycoconjugates (Figure 1).

Galectin-1 belongs to the proto-type family and was the first mammalian galectin identified. Despite considerable information

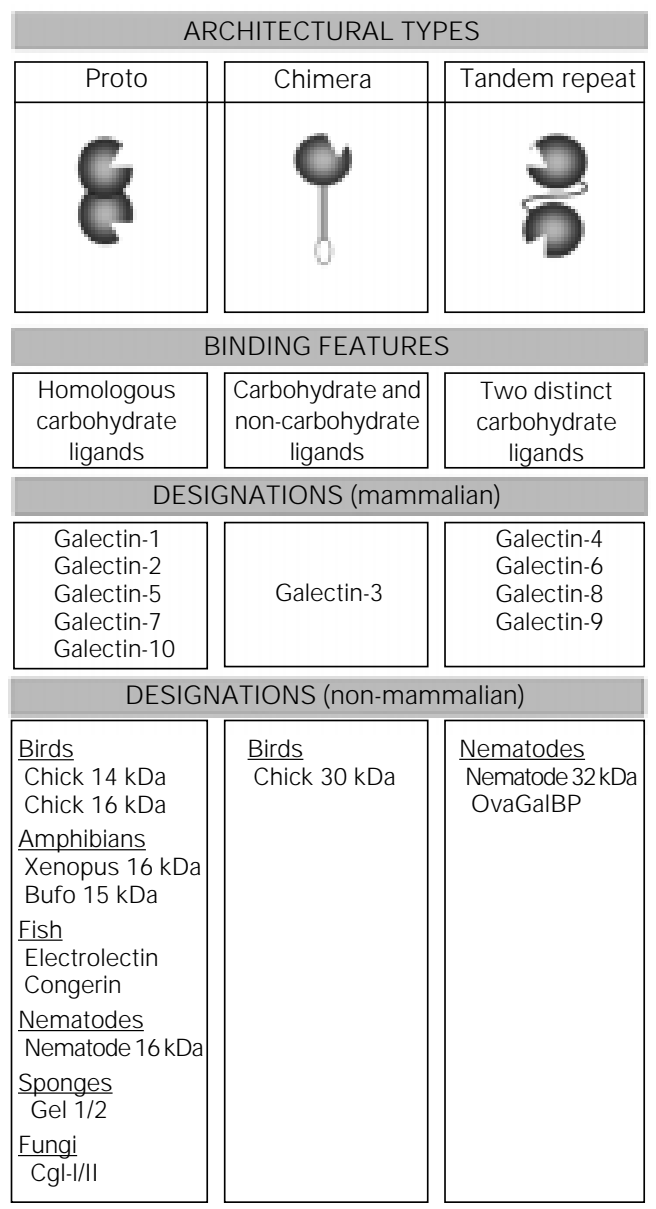

obtained at the biochemical and molecular level, its precise physiological functions after more than 20 years of active research still remain unclear. Table 1 shows the distribution of some galectin-1 in various tissues of diverse species. Studies of spatio-temporal distribution of this lectin have shown a highly conserved pattern throughout evolution. Its developmentally regulated expression strongly suggests that it could play a key role in some relevant physiological processes requiring protein-carbohydrate interactions $(1,7,8)$. In this context, functions have been assigned to galectin-1 in development, migration, cell adhesion and tumor metastasis (9-11).

Galectin-1 has been shown to exhibit specific immunomodulatory properties. Administration of exogenous galectin-1 showed therapeutic activity against the induction and progression of disease in two experimental animal models of autoimmunity, as described by Levi et al. (12) for myasthenia gravis and by Offner et al. (13) for autoimmune encephalomyelitis. Clear-cut evidence obtained from mouse strains which spontaneously develop autoimmune diseases and from more recent studies performed with transgenic or knockout mice clearly demonstrates that alteration of the cell death program of autoreactive lymphocytes is involved in the etiology of autoimmune diseases $(14,15)$.

In this context, recent investigations highlighted an additional role for galectin- 1 as a mediator of $\mathrm{T}$ cell apoptosis, the physiologic cell death of immature cortical thymocytes in the thymus (16), and also at the periphery at the level of mature T cells (17-19).

\section{Apoptosis in immune system homeostasis}

In multicellular organisms, homeostasis is maintained by an equilibrium between cell proliferation and cell death $(20,21)$. Cell proliferation is a highly regulated process with numerous check points. While growth 
factors and proto-oncogenes are positive regulators of the cell cycle, tumor suppressor genes such as p53 and Rb act to oppose uncontrolled proliferation by arresting cell cycle progression $(20,22)$. Physiologic cell death takes place primarily through an evolutionarily conserved form of cell suicide termed apoptosis $(23,24)$. The decision of a cell to undergo apoptosis can be influenced by a wide variety of extrinsic and intrinsic regulatory stimuli (25). This type of regulation allows the elimination of cells that have been produced in excess, have developed improperly, or have sustained genetic damage $(23,25)$. Although diverse signals can induce apoptosis in a wide variety of cell types, a number of evolutionarily conserved genes regulate a final common cell death pathway that is preserved from invertebrates to humans $(26,27)$.

In the immune system, a self-destructive process such as apoptosis must be under tight control to avoid unwanted effects, such as potentially autoreactive lymphocytes and excess cells after the completion of an immune response $(28,29)$. The presence of galectin-1 in primary and secondary lymphoid organs such as thymus, lymph nodes and spleen, in connection with the ability of this lectin to induce apoptosis of immature and mature $T$ cells, strongly suggests that this galectin may play an important role in the

Table 1 - Distributions and properties of galectin-1.

Reference 67 summarizes all the members of the galectin family so far identified.

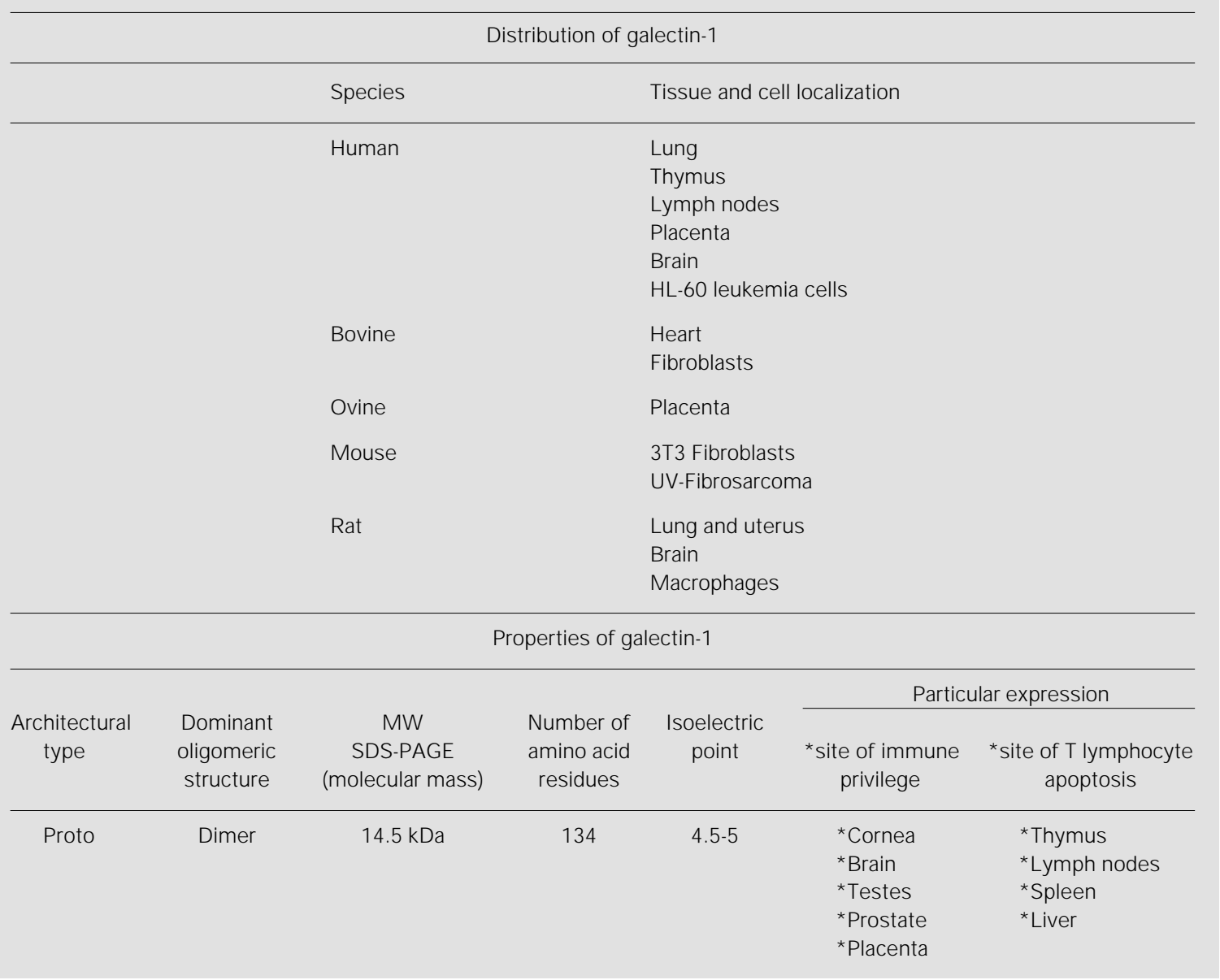


regulation of the immune response.

\section{Life and death in the thymus}

Apoptosis is a common event during $\mathrm{T}$ lymphocyte development for the production of immunocompetent $T$ cells (29). Large numbers of precursor cells migrate into the thymus daily, where they are subjected to selection in a critical process of thymic education. The majority of these cells die as result of neglect, since they are neither positively nor negatively selected (30). Those cells bearing $\mathrm{T}$ cell receptors (TCRs) that recognize self major histocompatibility complex proteins (MHC) are positively selected. Moreover, a subset of these cells recognizing MHC with the high affinity is subjected to negative selection and consequently deleted by apoptosis.

Death by neglect is definitely apoptotic (30) and occurs most probably via exposure to endogenous glucocorticoids (31). Thymocytes, in addition to the $\mathrm{T}$ cell line, are highly sensitive to apoptosis induced by glucocorticoids in an active process, requiring de novo gene expression (32). In this respect, Ashwell and colleagues $(33,34)$ performed in vivo experiments demonstrating that a subset of thymic epithelial cells are steroidogenic and that inhibition of steroid synthesis modified the profile of lymphoid thymic populations. Furthermore, data obtained by the creation of transgenic lines of mice carrying an antisense glucocorticoid receptor (34) indicated that thymocytes that do not bind to $\mathrm{MHC}$ are deleted by endogenous steroids.

Elimination of autoreactive lymphocytes may occur via activation-induced cell death: the same signals that trigger activation of peripheral mature $T$ cells induce apoptosis of thymocytes (35). The difference between positive selection of normally functional immature $T$ cells and elimination of autoreactive cells may lie in the affinity of their TCRs for self antigens and increasing evi- dence suggests that co-stimulatory signals could play an important role in this process (35-37). Furthermore, positive selection might also result from antagonism between glucocorticoid and activation-induced death. This model clearly suggests that thymocytes unable to bind to the MHC at all receive no stimulation through the $\mathrm{T}$ cell receptor complex and are eliminated via glucocorticoid signals, whereas thymocytes able to transduce TCR signals of sufficient strength to overwhelm the glucocorticoid pathway are eliminated via activation-induced cell death. In connection with these findings, an interesting study reports the overexpression of the human galectin-1 gene during glucocorticoid-induced cell death (38).

It is well known that thymocyte maturation requires the participation of thymic epithelial cells and extracellular matrix components $(39,40)$. In this context, Baum et al. (41) reported the expression of galectin- 1 by human thymic epithelial (TE) cells and demonstrated that this endogenous lectin mediates the adhesion of thymocytes to TE cells. This observation suggested that specific oligosaccharide sequences on immature thymocytes might be candidate ligands for galectin-1 synthesized by thymic stromal cells. Sensitivity of T cells to the lectin was found to be modulated by the expression of glycosyltransferase enzymes that may modify the availability of oligosaccharide ligands for galectin-1. Elucidation of the functional significance of this interaction provided concluding evidence that galectin-1 induced apoptosis of two distinct populations of nonselected and negatively selected CD4 ${ }^{\text {low }}$, CD8 ${ }^{\text {low }}$ immature cortical thymocytes (16).

\section{Death at the periphery}

In order to maintain cellular homeostasis and to protect activated mature $\mathrm{T}$ cells from continued secretion of potentially harmful levels of cytokines, activated cells are eliminated from the circulation by programmed 
cell death. Activation-induced apoptosis of mature $T$ cells occurs via Fas and Fas ligand (FasL) interactions. This has been clearly demonstrated in vitro using cell lines or $\mathrm{T}$ cell hybrids, which die in response to TCR binding $(42-44)$ as well as in vivo $(45,46)$ in spontaneous mutations in particular strains of MLR lpr/lpr or gld/gld mice, defective in Fas or FasL, respectively. In agreement, Nagata and colleagues (47) created Fas-/mice by targeted deletion of the Fas gene. These mice displayed enhanced and accelerated lymphoproliferation in comparison to $l p r / l p r$ mice (48). Following administration of Staphylococcus enterotoxin B to these null-mutant mice, dramatically impaired deletion occurred due to the absence of Fas antigen.

Fas is expressed on a wide variety of cell types including hematopoietic and epithelial cells. Expression of Fas on T and B lymphocytes increases after antigen receptor-mediated activation (49). In contrast to the widespread distribution of Fas, its ligand exhibits a highly restricted pattern of expression. FasL expression is induced on mature $\mathrm{CD} 4+$ and CD8 + $\mathrm{T}$ lymphocytes following activation but is not expressed by other hematopoietic cells $(50,51)$. FasL has also been reported to be constitutively expressed in two immunologically privileged tissues, such as the eye and the testis. Such expression could prevent damage inflicted by activated $T$ cells to these tissues. Although most tissues can tolerate the nonspecific damage caused by inflammatory responses, delicate tissues such as the eyes and the testis are susceptible to suffering irreparable damage after an inflammatory episode. Hence, expression of high levels of FasL represents a defensive mechanism to prevent damage caused by inflammation through an induction of apoptosis of activated cells expressing elevated levels of Fas antigen (52).

Despite striking similarities in their localization, critical differences should be highlighted between galectin-1 and FasL-induced apoptosis. At first sight, FasL triggers apoptosis by binding to Fas (CD95) through protein-protein interaction, whereas galectin-1 binds to cell surface glycoconjugates on thymocytes $(16)$ and mature $\mathrm{T}$ cells $(18,19)$. Besides, galectin-1 and FasL apparently use different signal transduction pathways to engage the apoptotic program of the cell. Recently, Su et al. (53) and Perillo et al. (18) showed that the $\mathrm{T}$ lymphoblastoid cell line MOLT-4, which was insensitive to FasLinduced apoptosis, was susceptible to galectin-1. In contrast, a $T$ lymphoblastoid cell line, which was sensitive to FasL, was resistant to the apoptotic effect of galectin-1. Moreover, since galectin-1 was capable of inducing apoptosis in the CD3-negative $\mathrm{T}$ lymphoblastoid cell lines, one should conclude that galectin-1 does not trigger apoptosis by cross-linking of the $\mathrm{T}$ cell receptor complex. These data strongly suggest that the mechanisms by which galectin-1 induced apoptosis are clearly distinct from those implicated in FasL- or T cell receptor-induced apoptosis.

Expression of galectin-1 in privileged immune sites, such as placenta, cornea and prostate $(8,54)$, may contribute to the maintenance of tolerance by inducing apoptosis of activated $\mathrm{T}$ cells responding to an injury, autoimmune damage or infection. Galectin1 was found to be upregulated by metastatic rather than noninvasive tumors. In a way, tumors could also be considered to be privileged immune tissues and several mechanisms for tumor evasion of immune recognition have been proposed, such as downregulation of MHC class I expression. In this context, one may suspect that galectins in tumor cells can trigger apoptosis of activated $\mathrm{T}$ cells, thus allowing the tumor to escape immune attack.

\section{Macrophages: key immunoregulatory cells at the periphery}

Macrophages (Møs) are key immuno- 
regulatory cells implicated in critical functions at the periphery, such as initiation of the immune response and regulation of the activities of other immune cell populations. These highly adaptive cells are able to modify their behavior in response to different environmental signals. In this sense, the peritoneal cavity has been a useful system for studying phenotypic differences between Mø populations (55). Resident, inflammatory and activated Møs show different profiles of enzymes and receptors which can be up- or down-regulated, and are closely related to the functional competence of these cells (55).

Since galectin-1 demonstrated immunomodulatory properties, we wondered whether this highly conserved structure could be present in Møs. If so, critical questions remain to be addressed: which is its precise biological function? Which is the cellular and molecular target of this function?

In an attempt to address this question, we performed immunochemical and immunocytochemical studies using a polyclonal antibody raised against the galectin. Mø-enriched populations were purified by plastic adherence from rat peritoneal cells and three different Mø subpopulations were defined. Resident Møs were obtained by washing the peritoneal cavity. Inflammatory Møs were recruited 3 days after intraperitoneal injection with proteose-peptone and activated Møs were obtained by in vivo or in vitro treatments, such as administration of Bacillus Calmette-Guerin and activation by LPS or by chemical agents such as PMA (phorbol ester) or chemoattractants such as fMLP (56).

Western blot analysis of total cell lysates obtained from the different stimulated Møs using the anti-galectin antibody revealed a single immunoreactive protein band corresponding to a molecular mass of $15 \mathrm{kDa}$ in all purified Mø population. By densitometric quantification we concluded that total expression of the $\beta$-galactoside-binding protein was increased about 5-fold in phorbol ester (PMA)- and chemotactic peptide
(fMLP)-activated Møs, and 2-fold in peptone-elicited inflammatory Møs. We performed flow cytometry experiments on the different Mø populations using fluoresceinlabeled ED1 mAb for the detection of monocyte macrophage lineage and phycoerythrinconjugated galectin antibody. Dual parameters counter plots showed a high proportion of double positive cells after exposure of cells to chemical agents such as PMA and fMLP (56). These results validate the concept that activation stimuli and different environmental signals can modulate the expression of this protein and suggest that this molecule could be involved in critical immunological processes mediated by Møs.

In order to explore the physiological significance of galectin overexpression in activated Møs, this rat macrophage galectin (RMGal) (19) was subjected to further purification and characterization. RMGal was purified from chemically activated Møs by single-step affinity chromatography on a lactosyl-Sepharose matrix. Sugars bearing a $ß$-D-galactoside configuration such as thiodigalactoside and lactose were able to inhibit the hemagglutinating activity displayed by this protein. Resembling the properties of this protein family, the purified galectin was resolved as a single protein band of $15 \mathrm{kDa}$ by SDS-PAGE with an isoelectric point of 4.8 , consistent with an acidic amino acid composition. Furthermore, gel filtration studies showed that the galectin behaved as a dimer under non-denaturing conditions (19).

To assure identity of the isolated protein, the internal amino acid sequence was determined and compared with previously described galectin sequences. Computer-assisted sequence library searches revealed high identity (of more than $80 \%$ ) between RMGal and other members of the mammalian galectin-1 subfamily particularly those found in rat lung and uterus (57), mouse 3T3 fibroblasts (58), bovine fibroblasts (59), and human placenta and brain $(60,61)$. These results indicated that RMGal shared all the 
critical residues found in other members of the mammalian galectin-1 subfamily. However, we do not rule out the possibility that it may be an alternative isoform of galectin-1, as described for chicken isolectins (62).

Since RMGal was overexpressed in activated immunoregulatory cells, the next issue we attempted to investigate was related to the role of this galectin in $\mathrm{T}$ cell death. Hence, mitogenically stimulated and nonstimulated spleen mononuclear cells were cultured in the presence of optimal concentrations of RMGal and then processed for DNA fragmentation, TUNEL assay and transmission electron microscopy. The electrophoretic pattern of genomic DNA extracted after $6 \mathrm{~h}$ of cell culture is shown in Figure $2 \mathrm{~A}$. The typical DNA ladder of oligonucleosome-sized fragments of $\sim 180-200$ bp was intensified in SpMs stimulated with Con A and exposed to RMGal (lane 3), and in SpMs incubated with RMGal alone at two different concentrations (lanes 4 and 5, respectively). In contrast, ladder type DNA fragmentation was almost absent in DNA extracted from SpMs cultured in medium alone (lane 1). Cells stimulated with Con A but not treated with RMGal showed the typical low intensity pattern of fragmentation characteristic of cell death following activation with mitogenic stimuli (lane 2). The same pattern was clearly observed when the $\mathrm{T}$ cell population was purified from total SpMs. Genomic DNA fragmentation was found to be particularly increased when RMGal was added to stimulated (lane 8), and nonstimulated (lane 9) T cells, in comparison to control of $\mathrm{T}$ cells in medium alone (lane 6) and T cells stimulated with Con A (lane 7). Thus, it should be emphasized that in our experimental conditions cell stimulation was not an essential step for RMGal-induced apoptosis.

In an attempt to quantify galectin-induced apoptosis, cells were cultured under the same conditions and processed for TUNEL detection using flow cytometry. As clearly shown in Figure 2B, 33\% of cells exposed to RMGal were apoptotic, as demonstrated by specific incorporation of biotinylated dUTP into DNA breaks, whereas control samples cultured in medium alone showed 5\% spontaneous apoptosis. The proportion of TUNEL-positive cells increased to $38 \%$ when the cells were simultaneously incubated with Con A and the lectin in comparison to cells cultured in the presence of Con A but not exposed to RMGal. The carbohydrate recognition domain of RMGal was involved in this function since a B-galactoside-related sugar, lactose, was able to induce a 33 to $11 \%$ decrease in levels of TUNEL-positive cells. In contrast, these effects were not significantly blocked when cells were exposed to the lectin in the presence of the specific antibody. Thus, induction of apoptosis by RMGal was highly specific and related to its carbohydrate-binding properties. Finally, ultrastructural studies of morphological changes induced by exposure to RMGal revealed the typical features of apoptosis (29) including reduction of the cytoplasmic volume, loss of surface microvilli, chromatin condensation and margination along the inner surface of the nuclear envelope (Figure 2C, panel 1 in comparison to panel 2). The results presented here provide clear-cut evidence indicating that the purified Mø galectin is associated with a positive control of the apoptotic threshold of T cells.

In the galectin family, galectin-1 promotes $\mathrm{T}$ cell apoptosis (16-19) and conversely, galectin-3 has been recently reported to be involved in the inhibition of the apoptotic cell program through an interaction with the $B c l-2$ proto-oncogene (63). The family of $\mathrm{Bcl}$-2-related proteins constitutes one of the most relevant apoptotic regulatory gene products acting on the effector stages of apoptosis (64). Within the $\mathrm{Bcl}-2$ family members, the ratio of death antagonists such as $B c l-2$ and $B c l-X_{L}$ to agonists such as $B a x$ and $\mathrm{Bad}$ determines whether a cell will respond to apoptotic signals. Hence, it seems meaningful that the interplay between 


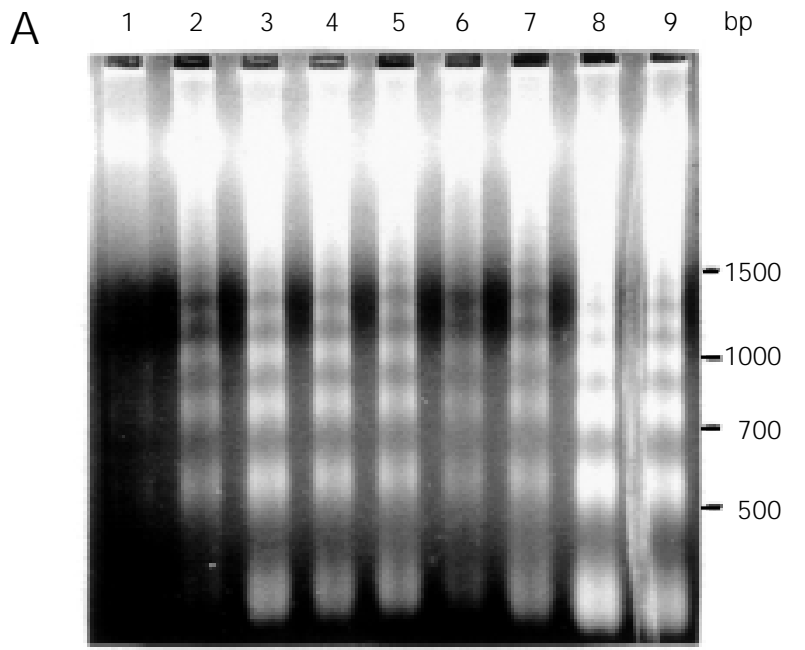

C

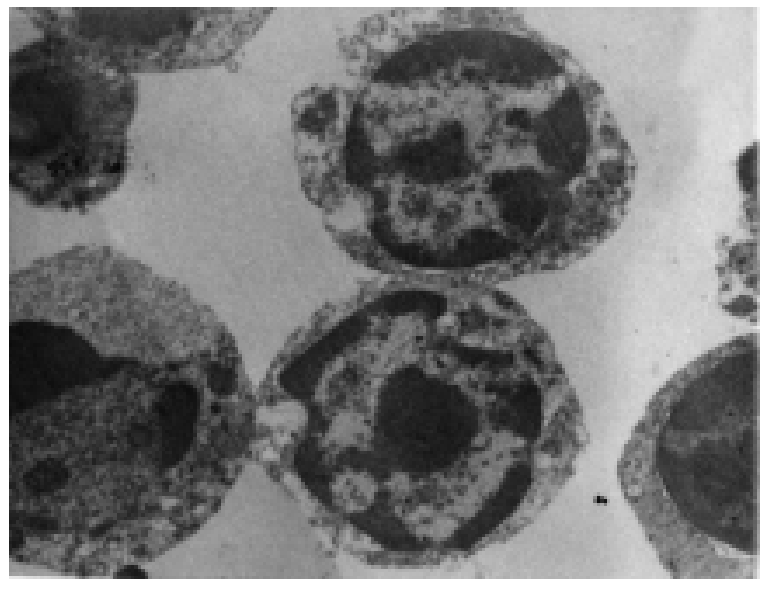

B
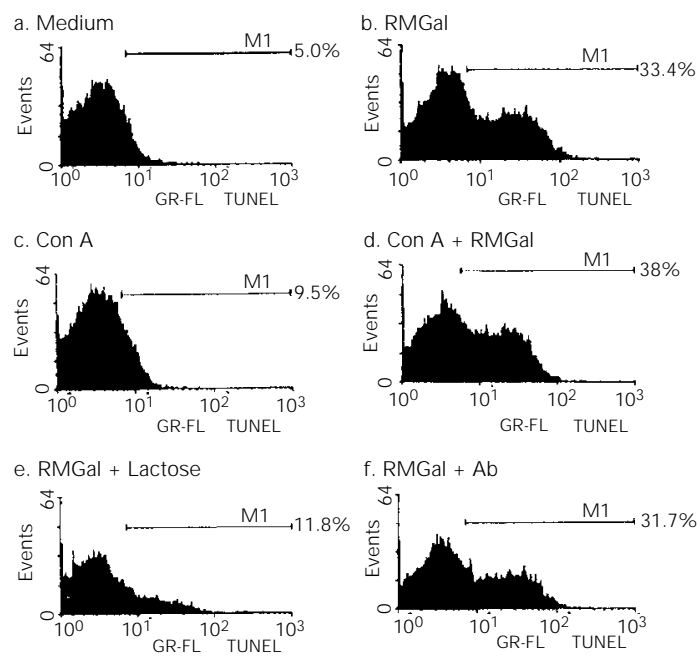

1

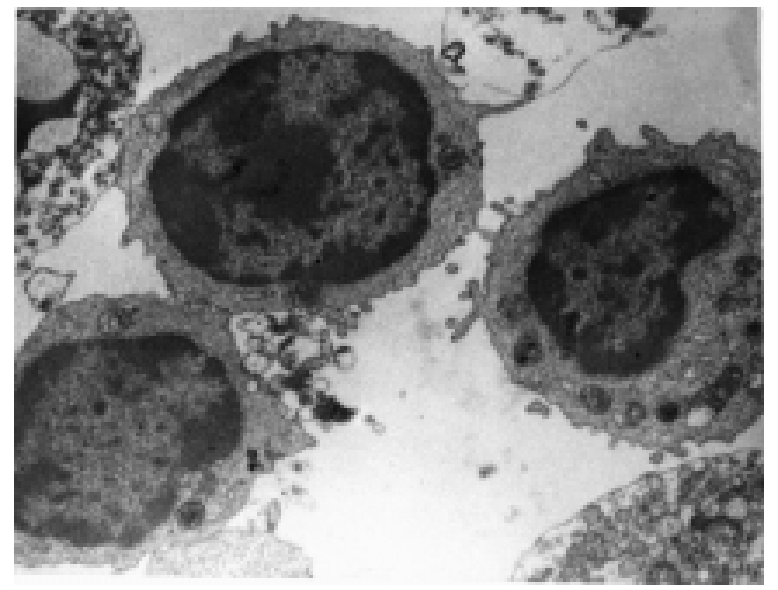

Figure 2 - Rat macrophage galectin induces apoptosis of T cells. A, Electrophoretic analysis of internucleosomal DNA fragmentation induced by RMGal. Spleen mononuclear cells were cultured in 24-well microtiter plates at a density of $2 \times 10^{7}$ cells/well for $6 \mathrm{~h}$ in medium alone (lane 1), in medium containing Con A, $2.5 \mu \mathrm{g} / \mathrm{ml}$ (lane 2), and in medium containing Con A, $2.5 \mu \mathrm{g} / \mathrm{ml}$, plus the addition of RMGal at a concentration of $4 \mu \mathrm{g} / \mathrm{ml}$ (lane 3). Cells were also cultured with RMGal (4 and $6 \mu \mathrm{g} /$ $\mathrm{ml}$ ) in the absence of a mitogenic stimulus (lanes 4 and 5, respectively). The $\mathrm{T}$ cell-enriched population was purified and cultured under identical conditions in medium alone (lane 6), in medium containing Con A (lane 7), in the presence of Con A plus RMGal, $4 \mu \mathrm{g} / \mathrm{ml}$ (lane 8), and in the presence of RMGal alone, $4 \mu \mathrm{g} / \mathrm{ml}$ (lane 9). Cells were then harvested and genomic DNA was extracted. Samples were diluted in loading buffer and resolved on $1.8 \%$ agarose gel. The relative mobility of oligonucleosome-length DNA fragments reflects integer multiples of $\sim 180-200 \mathrm{bp}$. M olecular standards (100 bp DNA ladder) are indicated on the right. $B$, Incorporation of biotinylated dUPT by exogenous TdT into DNA strand breaks generated after RMGal treatment. T cells $\left(2 \times 10^{7}\right.$ cells/well) were exposed to medium alone (a), $4 \mu \mathrm{g} / \mathrm{ml} \mathrm{RMGal} \mathrm{(b),} 2.5 \mu \mathrm{g} / \mathrm{ml}$ Con A (c), 2.5 $\mu \mathrm{g} / \mathrm{ml}$ Con A plus $4 \mu \mathrm{g} / \mathrm{ml} \mathrm{RMGal}(\mathrm{d}), 4 \mu \mathrm{g} / \mathrm{ml}$ RMGal in the presence of $100 \mathrm{mM}$ lactose (e), or $4 \mu \mathrm{g} / \mathrm{ml}$ RMGal in the presence of galectin $\mathrm{Ab}(\mathrm{f})$ for $6 \mathrm{~h}$ at $37^{\circ} \mathrm{C}$ in $5 \% \mathrm{CO}_{2}$. Samples were harvested, fixed, and permeabilized and the percentage of apoptotic cells in each sample was determined by flow cytometry analysis after TUNEL labeling. Cells treated with DNAse I were used as positive controls. C, Transmission electron microscopy examination of ultrastructural changes induced by RMGal. T cells were purified and cultured in 24-well plates at a density of $2 \times 10^{7}$ cells/well, in the presence (1), or in the absence (2) of RMGal ( $4 \mu \mathrm{g} / \mathrm{ml})$. After $6 \mathrm{~h}$, cells were harvested, washed and processed for transmission electron microscopy. Galectin-treated cells displayed the typical ultrastructural features compatible with apoptosis. Magnification: X12,000. (From J ournal of Immunology, 160: 4831-4840, 1998. Copyright 1998, The American Society of Immunologists). 
galectins- 1 and -3 could also represent an alternative pathway in the normal control of life, that is regulated by a delicate balance between cell proliferation, differentiation and death. In agreement with the results presented for RMGal, we also provided evidence that the chicken galectin CLL-I, which has $\sim 50 \%$ sequence similarities with galectin-1, inhibits growth of rat T cells via apoptosis, which proved to be controlled in a time-, lectin concentration- and a saccharide-dependent manner (65).

\section{Concluding remarks}

On the basis of the results reviewed herein, one would expect knockout mice for galectin-1 to show autoimmune manifestations such as lupus-like disorders, as observed for spontaneous mutations in Fas and FasL in MLR lpr/lpr or gld/gld mice, respectively. However, no important phenotypic changes could be detected in null mutant-mice as regards the galectin-1 gene. By contrast, these mice were found to be completely vital and proliferative (66). An exhaustive examination of the immunological system is imperative in these genetically modified mice not only at the central level but also at the periphery to search for potentially harmful autoaggressive clones and signs of disregulated apoptosis. Moreover, the possibility that other galectins identified thus far could compensate for the absence of this prototype galectin-1 protein should also be considered in future experimental work. Nevertheless, the novel role of a carbohydratebinding protein in the regulation of apoptosis provided a breakthrough in galectin research and widened the interphase between immunology, glycobiology and clinical medicine.

\section{Acknowledgments}

We thank Drs. Carlos Landa, Leonardo Castagna, Mercedes Iglesias, Nidia Modesti and Carlota-Wolfenstein Todel for their contribution.

\section{References}

1. Barondes SH, Cooper DNW, Gitt MA \& Leffler H (1994). Galectins: Structure and function of a large family of animal lectins. J ournal of Biological Chemistry, 269: 20807-20810.

2. Barondes SH, Castronovo V, Cooper DNW, Cummings RD, Drickamer K, Feizi T, Gitt MA, Hirabayashi J , Hughes C, Kasai K, Leffler H, Liu F, Lotan R, Mercurio AM, Monsigni M, Pillai S, Poirer F, Raz A, Rigby PWJ, Rini J M \& Wang JL (1994). Galectins: a family of animal beta galactoside-binding lectins. Cell, 76: 597-598.

3. Moonjae C \& Cummings RD (1997). Galectin-1: Oligomeric structure and interactions with polylactosamine. Trends in Glycoscience and Glycotechnology, 45: 47-56.

4. Cooper DNW (1997). Galectin-1: Secretion and modulation of cell interactions with laminin. Trends in Glycoscience and Glycotechnology, 45: 57-67.

5. Wang J L, Laing J G \& Anderson RL (1991). Lectin in the cell nucleus. Glycobiology, 1:
243-252.

6. Hirabayashi J \& Kasai K (1993). The family of metazoan metal-independent ß-galactoside-binding lectins: structure, function and molecular evolution. Glycobiology, 3: 297-304.

7. Barondes SH (1986). Vertebrate lectins: properties and functions. In: Lienner I, Sharon N \& Goldstein I (Editors), The Lectins: Properties, Functions and Applications in Biology and Medicine. Academic Press, Orlando, FL, 447-465.

8. Kasai K \& Hirabayashi J (1996). Galectins: a family of animal lectins that decipher glycocodes. J ournal of Biochemistry, 119: 1-8.

9. Adams $L$, Kenneth Scott $G \&$ Weinberg CS (1996). Biphasic modulation of cell growth by recombinant human galectin-1. Biochimica et Biophysica Acta, 1312: 137144.

10. Hughes RC (1992). Lectins as cell adhesion molecules. Current Opinion in Structural Biology, 2: 687-692.
11. Raz A \& Lotan R (1987). Endogenous galactoside-binding lectins: a new class of functional tumor cell surface molecules related to metastasis. Cancer and Metastasis Reviews, 6: 433-452.

12. Levi $\mathrm{G}$, Tarrab-Hazdai $\mathrm{R} \&$ Teichberg $\mathrm{VI}$ (1983). Prevention and therapy with electrolectin of experimental autoimmune myasthenia gravis in rabbits. European J ournal of Immunology, 13: 500-507.

13. Offner $H$, Celnik B, Bringman TS, Casentini-Borocz D, Nedwin GE \& Vandenbark A (1990). Recombinant human-galactoside-binding lectin suppresses clinical and histological signs of experimental autoimmune encephalomyelitis. J ournal of Neuroimmunology, 28: 177-184.

14. Singer GG, Carrera AC, MarshakRothstein A, Martínez-AC \& Abbas AK (1994). Apoptosis, Fas and systemic autoimmunity: the MRL Ipr/lpr model. Current Opinion in Immunology, 6: 913-920.

15. Watanabe-Fukunaga $\mathrm{R}, \mathrm{Brannan} \mathrm{Cl}$, 
Copeland NG, J enkins A \& Nagata S (1992). Lymphoproliferative disorder in mice explained by defects in Fas antigen that mediates apoptosis. Nature, 356: 314-317.

16. Perillo NL, Oittenbogaart $\mathrm{CH}$, Nguyen J T \& Baum LG (1997). Galectin-1, an endogenous lectin produced by thymic epithelial cells, induces apoptosis of human thymocytes. J ournal of Experimental Medicine, 97: 1851-1859.

17. Iglesias $M M$, Rabinovich GA, Ivanovic V, Sotomayor CE \& Wolfenstein-Todel C (1998). Galectin-1 from ovine placenta: complete primary structure, physicochemical properties and implications in the T cell death. European J ournal of Biochemistry, 252: 400-407.

18. Perillo NL, Pace KE, Seilhamer JJ \& Baum LG (1995). Apoptosis of T cells mediated by galectin-1. Nature, 378: 736-739.

19. Rabinovich GA, Iglesias MM, Modesti NM, Castagna L, Wolfenstein-Todel C, Riera CM \& Sotomayor CE (1998). Rat activated macrophages produce a galectin-1-like protein which induces apoptosis of T cells: Biochemical and functional characterization. J ournal of Immunology, 160: 4831-4840.

20. Evan $\mathrm{Gl}$, Brown L, Whyte $M \&$ \& Harrington E (1995). Apoptosis and the cell cycle. Current Opinion in Cell Biology, 7: 825834.

21. Grassilli E, Carcereri de Prati A, Monti D, Troiano L, Menegazzi $M$, Barbieri $D$, Franceschi C \& Suzuki H (1992). Studies of the relationship between cell proliferation and cell death. II. Early gene expression during concanavalin A-induced proliferation or dexamethasone-induced apoptosis of rat thymocytes. Biochemical and Biophysical Research Communications, 188: 1261-1266.

22. Hartwell LH \& Kastan MB (1994). Cell cycle control and cancer. Science, 266: 1821-1828.

23. Schwartzman RA \& Cidlowski J A (1993). Apoptosis: the biochemistry and molecular biology of programmed cell death. Endocrine Reviews, 14: 133-151.

24. Steller $H$ (1995). Mechanisms and genes of cellular suicide. Science, 267: 14451449.

25. Thompson CB (1995). Apoptosis in the pathogenesis and treatment of disease. Science, 267: 1456-1462.

26. Vaux DL, Haecker G \& Strasser A (1994). An evolutionary perspective on apoptosis. Cell, 76: 777-779.

27. Raff MC (1992). Social controls on cell survival and cell death. Nature, 356: 397-400.
28. Squier MKT, Sehnert AJ \& Cohen JJ (1995). Apoptosis in leukocytes. J ournal of Leukocyte Biology, 57: 2-10.

29. Cohen JJ, Duke RC, Fadok VA \& Sellins KS (1992). Apoptosis and programmed cell death in immunity. Annual Review of Immunology, 10: 267-293.

30. Surh CD \& Sprent J (1994). T-cell apoptosis detected in situ during positive and negative selection in the thymus. Nature, 372: 100-103.

31. Sprent J , Lo D, Gao EK \& Ron Y (1988). T cell selection in the thymus. Immunological Reviews, 101: 172-190.

32. Wyllie AH (1980). Glucocorticoid induced thymocyte apoptosis is associated with endogenous endonuclease activation. Nature, 284: 555-556.

33. Vacchio MS, Papadopulous V \& Ashwell J D (1994). Steroid production in the thymus: implications for thymocyte selection. J ournal of Experimental Medicine, 179: 1835-1846.

34. King LB, Vacchio MS, Hunziker R, Margulies DH \& Ashwell JD (1995). A targeted of glucocorticoid receptor antisense transgene increases thymocyte apoptosis and alters thymocyte development. Immunity, 5: 647-656.

35. Takayama H \& Sitkovsky MV (1989). Potential use of an antagonist of CAMP-dependent protein kinase to block inhibition and modulate T-cell receptor-triggered activation of cytotoxic T-lymphocytes. J ournal of Pharmaceutical Sciences, 78: 8-10.

36. Iwata $M$, Mukai $M$, Nakai $Y \&$ Iseki $R$ (1992). Retinoic acids inhibit activationinduced apoptosis in $\mathrm{T}$ cell hybridomas and thymocytes. J ournal of Immunology, 149: 3302-3308.

37. Migliorati G, Nicoletti I, Pagliacci MC \& Riccardi C (1992). Glucocorticoid-induced thymocyte apoptosis: inhibition by interleukin-2 and interleukin-4. Pharmacological Research, 25: 15-16.

38. Goldstone SD \& Lavin MF (1991). Isolation of a cDNA clone, encoding a humangalactoside-binding protein overexpressed during glucocorticoid-induced cell death. Biochemical and Biophysical Research Communications, 178: 746-750.

39. Anderson G, Owen JJT, Moore NC \& J enkinson EJ (1994). Thymic epithelial cells provide unique signals for positive selection of CD4+CD8+ thymocytes in vitro. J ournal of Experimental Medicine, 179: 2027-2031.

40. Anderson G, Moore NC, Owen JJT \& J enkinson EJ (1996). Cellular interactions in thymocyte development. Annual Review of Immunology, 14: 73-99.
41. Baum LG, Pang $M$, Perillo NL, Wu T, Delegeane A, Uittenbogaart $\mathrm{CH}$, Fukuda M \& Seilhamer JJ (1995). Human thymic epithelial cells express an endogenous lectin, galectin-1, which binds to core 20 glycans on thymocytes and $\mathrm{T}$ lymphoblastoid cells. J ournal of Experimental Medicine, 181: 877-887.

42. Dhein J, Walczak H, Baumler C, Debatin KM \& Kramer PH (1995). Autocrine T-cell suicide mediated by APO-1 (Fas/CD95). Nature, 373: 438-441.

43. Bruner T, Mogil RJ, LaFace D, Yoo NJ, Mahoubl A, Echeverri F, Martin SJ , Force WR, Lynch DH, Ware CF \& Green DR (1995). Cell-autonomous Fas (CD95)/Fasligand interaction mediates activation-induced apoptosis in T-cell hybridomas. Nature, 373: 441-444.

44. J u S-T, Panka DJ, Cul H, Ettinger R, ElKhatib M, Sherr DH, Stanger BZ\& MarsakRothstein A (1995). Fas (CD95)/FasL interactions required for programmed cell death after T-cell activation. Nature, 373: 444-448.

45. Russell J H, Rush B, Weaver $C \&$ Wang $R$ (1993). Mature T cells of autoimmune lpr/ Ipr mice have a defect in antigen-stimulated suicide. Proceedings of the National Academy of Sciences, USA, 90: 44094413.

46. Russell JH \& Wang R (1993). Autoimmune gld mutation uncouples suicide and cytokine/proliferation pathway in activated mature T cells. European J ournal of Immunology, 23: 2379-2382.

47. Adachi $M$, Suematsu $S$, Kondo $T$, Ogasawara J, Tanaka T, Yoshida N \& Nagata S (1995). Targeted mutation in the Fas gene causes hyperplasia in peripheral lymphoid organs and liver. Nature Genetics, 11: 294-300.

48. Adachi M, Suematsu S, Suda T, Watanabe D, Fukuyama H, Ogasawara J , Tanaka T, Yoshida N \& Nagata S (1996). Enhanced and accelerated lymphoproliferation in Fas-null-mice. Proceedings of the National Academy of Sciences, USA, 93: 21312136.

49. Nishimura $Y$, Ishií A, Kobayashi $Y$, Yamasaki Y \& Yonehara S (1995). Expression and function of mouse Fas antigen on immature and mature T cells. J ournal of Immunology, 154: 4395-4403.

50. Tanaka M, Suda T, Takanahashi $T \& \&$ Nagata S (1995). Expression of the functional soluble forms of the human Fas ligand in activated lymphocytes. EMBO J ournal, 14: 1129-1135.

51. Suda T, Okazaki T, Naito Y, Yokota T, Arai N, Ozaki S, Nakao K \& Nagata S (1995). 
Expression of the Fas ligand in cells of the $\mathrm{T}$ cell lineage. Journal of Immunology, 154: 3806-3813.

52. Osborne BA (1996). Apoptosis and the maintenance of homeostasis in the immune system. Current Opinion in Immunology, 8: 245-254.

53. Su ZZ, Lin J , Shen R, Fisher PE, Goldstein NI \& Fisher PB (1996). Surface-epitope masking and expression cloning identifies the human prostate carcinoma tumor antigen gene PCTA-1, a member of the galectin gene family. Proceedings of the $\mathrm{Na}-$ tional Academy of Sciences, USA, 93: 7252-7257.

54. Allen HJ , Sucato D, Gottstine S, Kisailus E, Nava H, Petrelli N, Castillo N \& Wilson D (1991). Localisation of endogenous beta-galactoside-binding lectin in human cells and tissues. Tumor Biology, 12: 5260.

55. Adams D \& Hamilton TA (1984). The cell biology of macrophage activation. Annual Review of Immunology, 2: 283-318.

56. Rabinovich GA, Castagna LF, Landa CA Riera CM \& Sotomayor CE (1996). Regulated expression of a 16-kd galectin-like protein in activated rat macrophages. J ournal of Leukocyte Biology, 59: 363-
370.

57. Clerch LB, Whitney P, Hass M, Brew K, Miller T, Werner R \& Massaro D (1988). Sequence of a full-length cDNA for rat lung B-galactoside-binding protein: Primary and secondary structure of the lectin. Biochemistry, 27: 692-699.

58. Wilson TJG, Firth MN, Powell JT \& Harrison FL (1989). The sequence of the mouse $14 \mathrm{kDa}$ ß-galactoside-binding lectin and evidence for its synthesis on free cytoplasmic ribosomes. Biochemical J ournal, 261: 847-852.

59. Abbott WM, Mellor A, Edwards $Y \&$ Feizi $T$ (1989). Soluble bovine galactoside-binding lectin CDNA reveals the complete amino acid sequence and an antigenic relationship with the major encephalitogenic domain of myelin basic protein. Biochemical J ournal, 259: 283-290.

60. Hirabayashi J \& Kasai K (1988). Complete amino acid sequence of a ß-galactosidebinding lectin from human placenta. J ournal of Biochemistry, 104: 1-4.

61. Bladier D, Le Caer J P, J oubert R, Caron M \& Rossier J (1991). B-galactoside soluble lectin from human brain: complete amino acid sequence. Neurochemistry International, 18: 275-283.
62. Beyer EC, Zweig SE \& Barondes SH (1980). Two lactose-binding lectins from chicken tissues. Purified lectin from intestine is different from those in liver and muscle. J ournal of Biological Chemistry, 255: 4236-4239.

63. Yang RY, Hsu DK \& Liu FT (1996). Expression of galectin-3 modulates T cell growth and apoptosis. Proceedings of the $\mathrm{Na}$ tional Academy of Sciences, USA, 93: 6737-6742.

64. Kroemer G (1997). The proto-oncogene $\mathrm{BCl}-2$ and its role in regulating apoptosis. Nature Medicine, 6: 614-620.

65. Rabinovich GA, Modesti N, Castagna LF, Landa C, Riera CM \& Sotomayor CE (1997). Specific inhibition of lymphocyte proliferation and induction of apoptosis by CLL-I, a ß-galactoside-binding lectin. J ournal of Biochemistry, 122: 365-373.

66. Poirrier F \& Robertson EJ (1993). Normal development of mice carrying a null mutation in the gene encoding the L14 Stype lectin. Development, 119: 12291236.

67. Leffler H (1997). Introduction to galectins. Trends in Glycoscience and Glycotechnology, 9: 9-19. 